\title{
LEI DE PROPRIEDADE INDUSTRIAL: Parágrafo Único do Artigo 40 da Lei 9.279/96 e Acesso a Medicamentos Genéricos
}

\author{
http://dx.doi.org/10.21527/2176-6622.2019.52.115-124
}

Recebido em: 1은/2019

Modificações requeridas em: 26/10/2019

Aceito em: 4/11/2019

\section{José Antonio Remedio}

Pós-doutor em Direito pela Universidade Estadual do Norte do Paraná (Uenp). Doutor em Direito do Estado pela Pontifícia Universidade Católica de São Paulo (PUCSP). Professor de Graduação e Pós-Graduação (Mestrado) em Direito da Universidade Metodista de Piracicaba (Unimep) e de Graduação em Direito do Centro Universitário Adventista de São Paulo (Unasp). Promotor de Justiça do Ministério Público do Estado de São Paulo aposentado. Advogado. http://lattes.cnpq.br/1121639468800540. jaremedio@yahoo.com.br

\section{Cristiane Canisela Villalva Prado}

Mestranda em Direito pela Universidade Metodista de Piracicaba (Unimep). Advogada. Farmacêutica-bioquímica pela Faculdade de Ciências Biológicas de Araras (FHO). http://lattes.cnpq.br/5129232526462805.

\section{RESUMO}

A presente pesquisa pretende avaliar os efeitos da aplicação do parágrafo único do artigo 40 da Lei de Propriedade Industrial, que confere possibilidade de prorrogação da vigência da patente em relação ao acesso aos medicamentos genéricos. Apresenta algumas reflexões sobre a proteção da propriedade intelectual enquanto direito fundamental. Verifica também a situação do processo de análise de pedidos de patentes de responsabilidade do Instituto Nacional de Propriedade Industrial (Inpi), como forma de entender o que levou o legislador a introduzir o referido parágrafo único no artigo 40 da Lei de Propriedade Industrial, especialmente no que se refere aos medicamentos genéricos. O método utilizado é o dedutivo, com base na revisão bibliográfica da legislação, doutrina e jurisprudência. Conclui que o parágrafo único do artigo 40 da Lei de Propriedade Industrial, que deveria ser utilizado apenas em casos excepcionais, é aplicado sistematicamente ante a questão do backlog. Conclui também que a aplicação do referido dispositivo normativo retarda a entrada de novos medicamentos genéricos no mercado, impedindo um maior acesso da população aos mesmos, em regra mais baratos, e tão seguros e eficazes quanto os medicamentos originais.

Palavras-chave: Lei de propriedade industrial. Medicamentos genéricos. Patente. Propriedade industrial. Prorrogação de patente.

\section{INDUSTRIAL PROPERTY LAW: SINGLE PARAGRAH FROM ARTICLE 40 OF THE LAW N. 9.279/96} AND THE ACCESS TO GENERIC MEDICINE

\section{ABSTRACT}

The present research intends to evaluate the effects of the application of the single paragraph from article 40 of the Industrial Property Law, which provides the possibility of extending the validity of the patent regarding the access to generic medicines. It presents a view about the protection of the intellectual property as a fundamental right. It also verifies the situation of the analysis of patent applications process, under the responsibility of the National Institute of Industrial Property (Inpi), as a way of understanding what led the legislator to introduce the aforementioned paragraph in article 40 of the Industrial Property Law, especially regarding generic medicines. The method used is the deductive, based on legislation bibliographical revision, doctrine and jurisprudence. It is concluded that the single paragraph of the article 40 of the Industrial Property Law, which should be used only in exceptional cases, is systematically applied in the context of backlog issues. It is also concluded that the application of this normative device delays the entry of new generic medicines in the market, preventing a greater access of the population to them, usually cheaper, and as safe and-effective as original medicines.

Keywords: Industrial property law. Generic medicine. Patent. Industrial property. Patent extension.

\section{SUMÁRIO}

1 Introdução. 2 Breves Considerações sobre a Proteção da Propriedade Intelectual. 30 Artigo 40 da Lei de Propriedade Industrial. 4 Medicamentos Genéricos. 5 Conclusão. 6 Referências. 


\section{INTRODUÇÃO}

A propriedade industrial integra o rol de direitos e garantias fundamentais e está prevista no artigo 50, inciso XXIX, da Constituição Federal de 1988. A Lei Maior assegura o direito subjetivo à proteção patentária aos autores de inventos industriais, desde que preenchidos os requisitos legais.

A concessão de patentes é de responsabilidade do Instituto Nacional de Propriedade Industrial (Inpi) e está regulamentada pela Lei 9.279/96, conhecida como Lei de Propriedade Industrial (LPI).

A norma constitucional determina que os autores de inventos gozarão de privilégio temporário para a sua utilização, visando o interesse social e o desenvolvimento tecnológico e econômico do país.

Os prazos para a exploração exclusiva estão estabelecidos na Lei de Propriedade Industrial, e são de 20 anos para a patente de invenção e de 15 anos para a de modelo de utilidade, o que obedece à previsão constitucional de temporariedade da patente.

O parágrafo único do artigo 40 da Lei de Propriedade Industrial, contudo, confere possibilidade de prorrogação da vigência da patente como forma de preservar o direito do inventor pela demora excessiva no processamento do pedido da patente.

Nesse contexto, a exploração exclusiva da patente, que deveria ter prazo inicial e final fixados previamente, passa a poder vigorar por prazo indeterminado, o que causa sérias consequências aos consumidores e fabricantes de medicamentos genéricos. Essa indeterminação faz com que versões genéricas de medicamentos demorem mais para entrar no mercado, causando sérios prejuízos aos cofres públicos e aos particulares.

A proteção conferida pelas patentes, em especial no setor farmacêutico, acarreta graves problemas para a saúde pública, em especial no que se refere aos elevados preços e ao desabastecimento dos medicamentos.

Nessa perspectiva é que se formula a presente pesquisa, objetivando discutir a proteção da propriedade intelectual no direito pátrio e as consequências da aplicação da prorrogação de parte da disposição constante do parágrafo único do artigo 40 da Lei de Propriedade Industrial.

No tocante à estrutura, a pesquisa está organizada em três partes, além da introdução: inicia-se com considerações a respeito da proteção da propriedade intelectual no Brasil; a seguir verifica a proteção e fundamentalidade da propriedade intelectual no Direito Pátrio; na sequência faz uma análise sobre o artigo 40 da Lei de Propriedade Industrial, com ênfase na situação do processo de análise de patentes no Brasil, notadamente as patentes farmacêuticas; e, por fim, realiza algumas reflexões sobre os medicamentos genéricos e as vantagens decorrentes de sua utilização.

A metodologia utilizada é a revisão bibliográfica de caráter dedutivo, a partir da análise da legislação, livros, artigos científicos, teses e jurisprudência aplicáveis ao tema.

Tem-se, como hipótese, que a prorrogação da vigência da patente, prevista no parágrafo único do artigo 40 da Lei de Propriedade Industrial, que deveria ocorrer apenas em casos excepcionais, vem sendo aplicada sistematicamente, retardando a entrada de novos medicamentos genéricos no mercado.

\section{BREVES CONSIDERAÇÕES SOBRE A PROTEÇÃO DA PROPRIEDADE INTELECTUAL}

A propriedade intelectual integra o rol de direitos e garantias fundamentais, estando contemplada no artigo 5o, inciso XXIX, da Constituição Federal de 1988 (CF/88), nos seguintes termos (BRASIL, 1988):

Art. 50 Todos são iguais perante a lei, sem distinção de qualquer natureza, garantindo-se aos brasileiros e aos estrangeiros residentes no País a inviolabilidade do direito à vida, à liberdade, à igualdade, à segurança e à propriedade, nos termos seguintes:

(...)

XXIX - a lei assegurará aos autores de inventos industriais privilégio temporário para sua utilização, bem como proteção às criações industriais, à propriedade das marcas, aos nomes de empresas e a outros signos distintivos, tendo em vista o interesse social e o desenvolvimento tecnológico e econômico do País. 
Dessa forma, a Lei Maior assegura o direito subjetivo à proteção patentária aos autores de inventos industriais, desde que preenchidos os requisitos legais. O mecanismo de concessão de patentes é vinculado e independe de juízo de conveniência e oportunidade por parte da União.

A lei referenciada no texto constitucional é a Lei 9.279/96, que trata da Propriedade Industrial (Lei de Propriedade Industrial - LPI), posto que a referida lei regula e disciplina os direitos e obrigações inerentes à propriedade industrial.

A proteção dos direitos relativos à propriedade industrial, considerados seu interesse social e o desenvolvimento tecnológico e econômico do país, efetua-se conforme o disposto no artigo 2 o da Lei 9.279/96, mediante concessão de patentes de invenção e de modelo de utilidade, concessão de registro de desenho industrial, concessão de registro de marca, repressão às falsas indicações geográficas e repressão à concorrência desleal. O Estado concede os direitos industriais por meio de uma autarquia federal: o Instituto Nacional da Propriedade Industrial (Inpi).

Em linhas gerais, a patente corresponde ao título de propriedade concedido pelo Estado, que assegura ao titular exclusividade temporária para exploração de uma determinada invenção (CHAVES; OLIVEIRA, 2007).

A proteção conferida pela Constituição Federal à propriedade intelectual tem caráter temporário e deriva de lei ordinária, a Lei de Propriedade Industrial. Para tanto, como todas as demais espécies de propriedade, a propriedade intelectual deve atender à sua função social, no caso representada pelo interesse social e pelo desenvolvimento tecnológico e econômico do país.

Desta forma, resta assegurado aos autores de inventos a possibilidade temporária de exploração exclusiva de seus inventos, ao mesmo tempo em que confere à sociedade em geral a possibilidade de exploração ou uso de tal invenção após o término da vigência da patente.

No âmbito internacional, a Convenção da Organização Mundial da Propriedade Intelectual - Ompi (Wipo em inglês) -, define a propriedade intelectual como (ABIMAQ, 2019)

[...] a soma dos direitos relativos às obras literárias, artísticas e científicas, às interpretações dos artistas intérpretes e às execuções dos artistas executantes, aos fonogramas e às emissões de radiodifusão, às invenções em todos os domínios da atividade humana, às descobertas científicas, aos desenhos e modelos industriais, às marcas industriais, comerciais e de serviço, bem como às firmas comerciais e denominações comerciais, à proteção contra a concorrência desleal e todos os outros direitos inerentes à atividade intelectual nos domínios industrial, científico, literário e artístico.

Ainda, de acordo com a OMPI, a propriedade intelectual é um tema de crescente importância para a economia do país, assim como um canal de inserção na comunidade internacional e, "juntamente com as patentes, é um instrumento essencial na difusão do conhecimento e na transformação do mesmo em benefícios sociais, influindo também na cooperação universidade-empresa, beneficiando ambas as partes e favorecendo o avanço tecnológico" (ABIMAQ, 2019).

A propriedade intelectual não é tema recente na história do Direito Brasileiro. A proteção jurídica destes bens constitui uma tradição antiga em nosso ordenamento jurídico, dada sua relevância para o desenvolvimento do país. O Brasil foi um dos primeiros países a legislar sobre a matéria, por meio do Alvará Régio de 28 de janeiro de 1809, promulgado pelo príncipe regente Dom João VI, que "previa a concessão do privilégio de exclusividade aos inventores e introdutores de novas máquinas e invenções, como benefício para a indústria e as artes" (BARRAL; PIMENTEL, 2006, p. 13).

A Constituição Federal protege a propriedade intelectual, que integra o Título II da CF/88, concernente aos direitos e garantias fundamentais, Capítulo I, relativo aos direitos e deveres individuais e coletivos.

A localização topográfica da propriedade intelectual entre os direitos e garantias fundamentais é alvo de discussões na doutrina. Alguns autores questionam a existência ou não de um direito natural aos bens intelectuais (PRONER, 2007, p. 139).

Silva (2014, p. 280) sustenta que, por não possuir natureza de direito fundamental do homem, a propriedade intelectual não deveria encontrar previsão no artigo 5o da $\mathrm{CF} / 88$, mas entre as normas sobre a ordem econômica. Além disso, assevera que o direito assegurado no dispositivo é de garantia relativa, e que decorrerá de legislação ordinária, isto é, a eficácia da norma depende de legislação ulterior. 
Nestes termos, a norma possui eficácia limitada e sua aplicação é mediata, o que contraria o disposto no $\S 1$ 얼 do artigo 5 o da CF/88, que estabelece que a aplicação das normas definidoras dos direitos e garantias fundamentais é imediata (BASSO, 2008, p. 41).

Trata-se de um direito subjetivo assegurado aos autores de inventos industriais, desde que preenchidos os requisitos previstos na Lei de Propriedade Industrial.

No mesmo sentido manifestou-se a Organização das Nações Unidas (ONU), por intermédio da Comissão dos Direitos Econômicos, Sociais e Culturais. Segundo o Comentário Geral n. 7, de novembro de 2005, a propriedade intelectual não possui natureza de direito fundamental do homem (UNITED NATIONS, 2005):

1. O direito de todos se beneficiarem da proteção dos interesses morais e materiais resultantes de qualquer produção científica, literária ou artística da qual ele ou ela seja o autor é um direito humano, que deriva da dignidade e valor inerentes a todas as pessoas.(...). Direitos humanos são direitos fundamentais, inalienáveis e universais pertencentes a indivíduos e, sob certas circunstâncias, grupos de indivíduos e comunidades. Os direitos humanos são fundamentais, pois são inerentes à pessoa humana como tal, enquanto os direitos de propriedade intelectual são, antes de mais nada, meios pelos quais os Estados procuram incentivar a inventividade e a criatividade, incentivar a divulgação de produções criativas e inovadoras, bem como o desenvolvimento de identidades culturais e preservar a integridade das produções científicas, literárias e artísticas para o benefício da sociedade como um todo.

2. Ao contrário dos direitos humanos, os direitos de propriedade intelectual são geralmente de natureza temporária e podem ser revogados, licenciados ou atribuídos a outra pessoa. Enquanto na maioria dos sistemas de propriedade intelectual, os direitos de propriedade intelectual, muitas vezes com exceção dos direitos morais, podem ser alocados, limitados no tempo e escopo, comercializados, alterados e até confiscados, os direitos humanos são expressões atemporais dos direitos fundamentais da pessoa humana.(...). ${ }^{1}$ (tradução nossa).

Em sentido contrário, porém, Maristela Basso (2008, p. 41) entende que, apesar das discussões a respeito, a propriedade intelectual deve integrar o rol das garantias fundamentais, desde que atendida sua função social:

Muito embora exista na doutrina a discussão sobre sua natureza jurídica, o certo é que a propriedade industrial, nos termos da Carta de 5 de outubro de 1988, e desde a Constituição do Império de 1824, é uma espécie de propriedade com matriz constitucional, sendo um conceito de propriedade paralelo ao clássico, embora seja a nossa opinião que devesse fazer-se incluir no elenco das garantias fundamentais. E, estando a "propriedade geral" do art. 5o, inciso XXII, submetida ao atendimento de sua função social (art. 5o, XXIII), é possível relacionar essa condição também ao exercício da propriedade industrial.

Ainda de acordo com a autora, quando a Constituição faz menção à propriedade, esta engloba todos os direitos patrimoniais privados. Neste sentido, os direitos intelectuais, apesar de possuírem faculdades específicas, também possuem características de direitos patrimoniais privados (BASSO, 2008, p. 41).

\section{O ARTIGO 40 DA LEI DE PROPRIEDADE INDUSTRIAL}

A Propriedade Industrial é o ramo da Propriedade Intelectual que trata das "criações intelectuais voltadas para as atividades de indústria, comércio e prestação de serviços e engloba a proteção das invenções (patente de invenção e modelo de utilidade), desenhos industriais, marcas, indicações geográficas, bem como

\footnotetext{
1 Texto original em inglês:

"1. The right of everyone to benefit from the protection of the moral and material interests resulting from any scientific, literary or artistic production of which he or she is the author is a human right, which derives from the inherent dignity and worth of all persons. (...) Human rights are fundamental, inalienable and universal entitlements belonging to individuals and, under certain circumstances, groups of individuals and communities. Human rights are fundamental as they are inherent to the human person as such, whereas intellectual property rights are first and foremost means by which States seek to provide incentives for inventiveness and creativity, encourage the dissemination of creative and innovative productions, as well as the development of cultural identities, and preserve the integrity of scientific, literary and artistic productions for the benefit of society as a whole.

2. In contrast to human rights, intellectual property rights are generally of a temporary nature, and can be revoked, licensed or assigned to someone else. While under most intellectual property systems, intellectual property rights, often with the exception of moral rights, may be allocated, limited in time and scope, traded, amended and even forfeited, human rights are timeless expressions of fundamental entitlements of the human person."
} 
a repressão da concorrência desleal". No Brasil, o Sistema de Propriedade Industrial é constituído basicamente pela Lei da Propriedade Industrial, a Convenção de Paris, os Tratados Internacionais e os Atos Normativos e Resoluções do Instituto Nacional da Propriedade Industrial (Inpi) (ABIMAQ, 2019).

No país, a vigência da patente decorre especialmente da Lei 9.279/96. Nos termos do artigo 40 do referido diploma normativo (BRASIL, 1996), traz:

Art. 40. A patente de invenção vigorará pelo prazo de 20 (vinte) anos e a de modelo de utilidade pelo prazo 15 (quinze) anos contados da data de depósito.

Parágrafo único. O prazo de vigência não será inferior a 10 (dez) anos para a patente de invenção e a 7 (sete) anos para a patente de modelo de utilidade, a contar da data de concessão, ressalvada a hipótese de o INPI estar impedido de proceder ao exame de mérito do pedido, por pendência judicial comprovada ou por motivo de força maior.

Da redação do dispositivo citado pode-se notar que o prazo de vigência da patente de invenção é de 20 anos, enquanto o prazo da patente de modelo de utilidade é de 15 anos, contados a partir da data do depósito do pedido no Inpi, o que obedece à temporariedade da proteção prevista na norma constitucional.

Segundo Paesani (2012, p. 41), os prazos previstos no caput do artigo 40 da Lei de Propriedade Industrial não são renováveis. O parágrafo único do dispositivo prevê, no entanto, um prazo mínimo de vigência para as patentes a partir da concessão, a saber, dez anos para a patente de invenção e sete anos para a patente de modelo de utilidade, como forma de compensar o titular do direito pelo atraso excessivo no processamento de seu pedido junto ao Inpi.

O processamento de pedidos de concessão de patentes, todavia, tem sido marcado por excessiva demora, seja no Brasil, seja no exterior. Especificamente no Brasil, o Inpi há anos vem enfrentando sérias dificuldades relativas ao prazo de concessão de patentes. Atualmente, a autarquia possui um número bastante elevado de pedidos de patentes pendentes, o chamado backlog (SPADANO; SANTOS; TÂNGARI, 2017).

Com base em dados estatísticos disponíveis no site do Inpi, pode-se ter uma noção da situação dos pedidos de patentes. Em junho de 2017 havia 231.184 pedidos de patentes pendentes de exames. Levando-se em consideração que o Inpi conta com 326 examinadores e o índice de produtividade é de 55 decisões em exame técnico por examinador por ano, se não forem tomadas medidas do Órgão que reduzam significativamente o número de exames pendentes, a tendência é de que em 2029 esse número chegue a 349.080 pedidos na fila de espera (INPI, 2017 ).

A ineficiência do Inpi gera um ambiente de insegurança e de desestímulo aos investimentos no Brasil, comprometendo o desenvolvimento do país e, consequentemente, causando prejuízos incalculáveis, tanto para o poder público quanto para os consumidores e a iniciativa privada.

O próprio presidente do Inpi, Luiz Otávio Pimentel, confirma a morosidade para a obtenção de uma patente no Brasil. Segundo suas palavras, "o trâmite de uma patente hoje está estimado em 10 anos e 9 meses. A nossa capacidade de exame técnico hoje é de cerca de 9 mil patentes por ano. E, nos últimos 3 anos, a média de pedidos junto ao Inpi tem sido de 30 mil pedidos. Então nós estamos sempre aquém" (JORNAL, 2017).

Na seara farmacêutica, a estatística baseada nos anos de 2016 e 2017 indica que os pedidos de patentes têm sido concedidos, em média, mais de 12 anos após o depósito (INPI, 2017 ).

Como os direitos de propriedade industrial devem refletir o interesse social, foi editada a Resolução $80 / 2013$, do Inpi, que disciplina a priorização do exame de pedidos de patente de produtos e processos farmacêuticos, bem como equipamentos e materiais relacionados à saúde pública, com o objetivo de dar celeridade ao exame de pedidos de patente relacionados aos produtos, processos, equipamentos e materiais de uso em saúde, em particular aqueles considerados estratégicos no âmbito do Sistema Único de Saúde (SUS). Sendo assim, ao menos formalmente, desde então esses pedidos têm prioridade na fila de espera.

Conforme estimativa realizada pelo Instituto de Economia da Universidade Federal do Rio de Janeiro, porém, o atual processo faz com que a patente fique vigente além do prazo legal, entre 1,75 e 5,58 anos adicionais. A análise foi feita com 7 medicamentos usados no tratamento de hepatite, HIV/Aids e artrite reumatoide, entre outros, resultando no gasto adicional, pelo Ministério da Saúde, de R\$2,02 bilhões até 2016 (ANVISA, 2017b). 
Diante deste cenário de morosidade excessiva na análise dos pedidos de patentes por parte do Inpi e da possibilidade de prorrogação do prazo de vigência da patente que o parágrafo único do artigo 40 da Lei de Propriedade Industrial contempla, tem-se que a proteção patentária irá ultrapassar os prazos previstos no caput do artigo 40, que é de 20 anos para patentes de invenção e de 15 anos para patente de utilidade.

A possibilidade de exploração exclusiva da patente por prazo indeterminado gera grande insegurança e viola sua função social, qual seja, o interesse público e o desenvolvimento tecnológico e econômico do país. O prolongamento da vigência de uma patente farmacêutica impede que novos medicamentos genéricos entrem no mercado. As consequências disso decorrentes podem ser desastrosas, como gastos desnecessários ao Ministério da Saúde e menor acesso da população a medicamentos com preços mais acessíveis.

O Superior Tribunal de Justiça, ao julgar o Recurso Especial 1.721.711-RJ (BRASIL, 2018) relacionado a medicamentos, sufragou o entendimento no sentido de que o adiamento da entrada das invenções em domínio público "significa retardar o acesso ao mercado de genéricos, causando, como consequência, o prolongamento de preços mais altos, o que contribui para a oneração das políticas públicas de saúde e dificulta o acesso da população a tratamentos imprescindíveis".

Por sua vez, o Tribunal Regional Federal da 2a Região, ao julgar a Apelação e Reexame Necessário n. 0132260-18.2013.4.02.5101, decidiu que "o parágrafo único do artigo 40 da Lei n. 9.279/96 ofende o caráter temporário dos privilégios sobre patente (inciso XXIX do artigo 5ㅇ) ao conferir prazo indefinido à vigência desses registros" (BRASIL, 2015).

\section{MEDICAMENTOS GENÉRICOS}

No Brasil, as primeiras discussões sobre medicamentos genéricos tiveram início na década de 70 , e resultaram na publicação do Decreto 793/73, posteriormente revogado pelo Decreto 3.181/99, que regulamentou a Lei 9.787/19.

A Lei 9.787/99 alterou alguns dispositivos da Lei 6.360/76, que dispõe sobre a Vigilância Sanitária, e introduziu, de modo formal, a questão da denominação genérica e de medicamentos genéricos no país, em consonância com as normas estabelecidas pela Organização Mundial da Saúde (OMS), países da Europa, Estados Unidos e Canadá.

Os primeiros registros de medicamentos genéricos datam do ano 2.000, quando foram concedidos 182 registros e tomadas as ações para instituir a produção dessa espécie de medicamento, inclusive com incentivo à importação (ANVISA, 2018a).

Antes de quaisquer considerações acerca dos medicamentos genéricos, é mister diferenciá-los dos medicamentos de referência e dos medicamentos similares.

Considera-se medicamento de referência, consoante artigo 3ㅇ, inciso XXII, da Lei 9.787/99, o produto inovador registrado no órgão federal responsável pela Vigilância Sanitária e comercializado no país, cuja eficácia, segurança e qualidade foram comprovadas cientificamente junto ao órgão federal competente por ocasião do registro.

Tem-se como medicamento similar, conforme artigo 3ㅇ, inciso XX, da Lei 9.787/99, aquele que contém o mesmo ou os mesmos princípios ativos, apresenta a mesma concentração, forma farmacêutica, via de administração, posologia e indicação terapêutica, preventiva ou diagnóstica, do medicamento de referência registrado no órgão federal responsável pela vigilância sanitária, podendo diferir somente em características relativas ao tamanho e à forma do produto, prazo de validade, embalagem, rotulagem, excipientes e veículos, devendo sempre ser identificado por nome comercial ou marca.

Considera-se medicamento genérico, de acordo com o artigo 3e, inciso XXI, da Lei 9.787/99, o medicamento similar a um produto de referência ou inovador, que se pretende ser com este intercambiável, geralmente produzido após a expiração ou renúncia da proteção patentária ou de outros direitos de exclusividade, comprovada a sua eficácia, segurança e qualidade, e designado pela Denominação Comum Brasileira (DCB) ${ }^{2}$ ou, na sua ausência, pela Denominação Comum Internacional (DCI). ${ }^{3}$

\footnotetext{
Denominação Comum Brasileira (DCB) - denominação do fármaco ou princípio farmacologicamente ativo aprovada pelo órgão federal responsável pela Vigilância Sanitária.

3 Denominação Comum Internacional (DCl) - denominação do fármaco ou princípio farmacologicamente ativo recomendada pela Organização Mundial de Saúde.
} 
O medicamento genérico contém o mesmo princípio ativo, dose, forma farmacêutica, administração de via e indicação terapêutica do medicamento de referência. Não possui nome comercial e seu custo deve ser no mínimo 35\% inferior ao produto de marca. As embalagens devem apresentar uma tarja amarela com a letra "G" e a indicação "Medicamento Genérico". Medicamentos genéricos podem substituir os medicamentos de marca, sendo, portanto, considerados intercambiáveis (LISTA, 2018).

A intercambialidade é garantida por meio de testes de equivalência terapêutica, que incluem comparação in vitro, mediante estudos de equivalência farmacêutica, e in vivo, com os testes de bioequivalência apresentados à Agência Nacional de Vigilância Sanitária (ANVISA, 2018a).

A introdução de políticas públicas quanto ao uso de medicamentos genéricos pode "contribuir na promoção de uma maior acessibilidade, redução de custos, aumento de alternativas, além de contribuir na racionalização da seleção e do uso de medicamentos" (BERMUDEZ, 1999, p. 158).

Segundo dados da Anvisa, desde o ano de 2000, quando iniciaram as concessões dos primeiros registros, até 30 de junho de 2017, 4.886 medicamentos genéricos foram registrados, posto que, deste montante, 1.016 tiveram seus registros cancelados, restando um saldo de 3.870 medicamentos genéricos com registros válidos (ANVISA, 2018b).

No período em questão, 120 empresas eram detentoras dos registros válidos, considerando que 85,6\% dos medicamentos genéricos com registro válido são fabricados no Brasil. Do restante, entre outros, 8,3\% são fabricados na Índia, 1,1\% na Alemanha, 0,7\% no Canadá, 0,3 na Itália e 0,3\% nos Estados Unidos da América.

No Brasil, as vantagens na utilização dos medicamentos genéricos são bastante expressivas. Segundo dados do Conselho Federal de Farmácia (CFF), em 2016 o Brasil ocupava a sexta posição entre os maiores consumidores de medicamentos do mundo, com projeção, segundo a IMS Health, de alcançar a quarta posição até 2018, atrás apenas de Estados Unidos, China e Japão (CFF, 2016).

Tal consumo deve-se, em grande parte, ao envelhecimento da população brasileira. Conforme estimativas do Instituto Brasileiro de Geografia e Estatística (IBGE), a população acima dos 60 anos de idade deve passar de 14,9 milhões (7,4\% do total), em 2013 , para 58,4 milhões (26,7\% do total) até 2060 , graças ao aumento da expectativa de vida (CFF, 2016).

Como é notório, é justamente na velhice que doenças crônicas, como hipertensão e diabetes, tendem a se manifestar com maior frequência, causando expressivo aumento no consumo de medicamentos.

Além disso, os medicamentos são um dos maiores responsáveis pelos gastos com saúde pública. Segundo a Anvisa, em 2016 o faturamento do setor farmacêutico industrial foi de R\$ 63,5 bilhões, posto que 15\% deste valor, ou seja, $\mathrm{R} \$$ 9.719.138.198,00, foram comercializados com o governo (ANVISA, 2017a). Cabe ressaltar que o faturamento das indústrias com medicamentos genéricos somou $R \$$ 8.581.021.119,00 no mesmo ano.

A Lei 8.080/90, que trata das condições para a promoção, proteção e recuperação da saúde, a organização e o funcionamento dos serviços correspondentes, estabelece que a saúde é um direito fundamental do ser humano, devendo o Estado prover as condições indispensáveis ao seu pleno exercício por meio da formulação e execução de políticas econômicas e sociais que visem à redução de riscos de doenças e de outros agravos e do estabelecimento de condições que assegurem acesso universal e igualitário às ações e aos serviços para a sua promoção, proteção e recuperação (artigo 1ํ).

Ademais, a referida Lei dispõe que os níveis de saúde expressam a organização social e econômica do país, tendo a saúde como determinantes e condicionantes, entre outros, a alimentação, a moradia, o saneamento básico, o meio ambiente, o trabalho, a renda, a educação, a atividade física, o transporte, o lazer e o acesso aos bens e serviços essenciais (artigo $3 \%$ ).

É importante salientar que a Organização Mundial de Saúde (OMS) destaca que ocorre uso racional de medicamentos quando os pacientes recebem medicamentos adequados às suas condições clínicas, em doses ideais para suas necessidades individuais e ao menor custo para si e para a comunidade (WHO, 1985). 
Os medicamentos genéricos, por disposição legal, ${ }^{4}$ devem ser, no mínimo, $35 \%$ mais baratos que os medicamentos de referência. Podem ser produzidos apenas após o término do prazo de proteção patentária do medicamento original. São cópias fiéis das fórmulas já existentes e, pelo fato de os fabricantes não precisarem investir quantias enormes em pesquisa e desenvolvimento, chegam ao mercado com preços mais acessíveis.

Desta forma, amplia o acesso da população a medicamentos seguros, eficazes e de qualidade comprovada. Isto porque os medicamentos genéricos somente podem ser comercializados após serem aprovados em testes de equivalência farmacêutica ${ }^{5}$ e bioequivalência, ${ }^{6}$ segundo as normas da Anvisa (PRÓ-GENÉRICOS, 2018).

Além disso, estimulam a concorrência, fazendo com que os preços dos medicamentos de referência sejam reduzidos, beneficiando todos os que necessitam de medicamentos, sobretudo a população mais carente e portadora de doenças crônicas.

Ademais, medicamentos genéricos podem substituir os medicamentos de referência prescritos nas receitas médicas, oportunizando uma alternativa segura e eficaz de viabilização dos tratamentos a preços mais baratos.

\section{CONCLUSÃO}

O direito à proteção patentária está expressamente previsto no artigo 5으, inciso XXIX, da Constituição Federal de 1988, integrando o rol de direitos e garantias fundamentais.

Trata-se de um direito subjetivo assegurado aos autores de inventos industriais, desde que preenchidos os requisitos previstos na Lei 9.279/96, a Lei de Propriedade Industrial.

O Instituto Nacional da Propriedade Industrial (Inpi) é o órgão responsável por processar os pedidos de patentes e analisar se estão presentes os requisitos de patenteabilidade, conforme determina a Lei de Propriedade Industrial.

A Constituição Federal deixa claro a temporariedade da exploração exclusiva da patente, desde que atendida sua função social, neste caso representada pelo interesse social e pelo desenvolvimento tecnológico e econômico do país.

A exclusividade da exploração patentária tem seu prazo previsto no artigo 40 da Lei de Propriedade Industrial, sendo de 20 anos para a patente de invenção e de 15 anos para a de modelo de utilidade.

O parágrafo único do artigo 40 da Lei $9.279 / 96$, contudo, confere possibilidade de prorrogação da vigência da patente como forma de preservar o direito do inventor por uma possível demora no processamento do pedido da patente.

Em razão da demora sistemática no processamento de pedidos de patentes por parte do Inpi, no entanto, a patente passou a ter uma vigência maior que aquela inicialmente prevista no caput do artigo 40 da Lei de Propriedade Industrial. Assim, a exploração exclusiva da patente farmacêutica, que deveria ter prazo inicial e final fixados previamente num total de 20 anos, passa a poder vigorar por prazo indeterminado, conforme estudos, entre 1,75 e 5,58 anos adicionais. Essa indeterminação faz com que versões genéricas de medicamentos demorem mais para entrar no mercado, causando sérios prejuízos aos cofres públicos e aos particulares.

Os medicamentos genéricos são muito importantes na promoção da saúde, pois são, no mínimo, 35\% mais baratos que os medicamentos originais, o que permite que um maior número de pessoas tenha acesso a tratamentos eficientes, seguros e de baixo custo.

\footnotetext{
4 Nesse sentido, a Resolução n. 2, de 2004, da Câmara de Regulação do Mercado de Medicamentos (CMED).

5 Os testes de equivalência farmacêutica têm por objetivo comprovar que os genéricos possuem os mesmos fármacos, na mesma dosagem e forma farmacêutica encontradas nos medicamentos de referência, além de cumprirem com as mesmas especificações físicas e físicoquímicas relativas ao controle de qualidade.

6 Os testes de bioequivalência são realizados em voluntários sadios e obedecem a três fases: a fase clínica, quando ocorre a administração do medicamento genérico e de referência em períodos distintos, com a coleta de amostras de sangue ou urina em tempos determinados; a fase analítica, na qual é feita a quantificação do fármaco nas amostras por meio de método específico; e a fase estatística, em que são realizados cálculo dos parâmetros farmacocinéticos e análise estatística para determinar a bioequivalência.
} 
Sugere-se, com o estudo, sem a pretensão de se enveredar para o esgotamento do tema, que o parágrafo único do artigo 40 da Lei 9.279/96 seja revisto, e que o Poder Público dê maiores e melhores condições de atuação e trabalho ao Inpi, a fim de evitar atrasos nos processamentos de pedidos de patentes, e assim assegurar o acesso da população aos medicamentos genéricos.

Tem-se, em conclusão, que restou demonstrada a hipótese inicial, no sentido de que o parágrafo único do artigo 40 da Lei de Propriedade Industrial é aplicado sistematicamente ante a morosidade da análise dos pedidos de patentes pelo Inpi, retardando a entrada de novos medicamentos genéricos no mercado e, consequentemente, impedindo um maior acesso da população aos mesmos.

\section{REFERÊNCIAS}

ABIMAQ. Manual Propriedade Industrial - Abimaq/IPD-Maq - Núcleo de Apoio ao Patenteamento. 2019. Disponível em: https://vdocuments.com.br/propriedade-intelectual-definicao-a-convencao-da-.html. Acesso em: 7 abr. 2019.

ANVISA. Agência Nacional de Vigilância Sanitária. Anuário estatístico do mercado farmacêutico 2016. Brasília, 2017a. Disponível em: http://portal.anvisa.gov.br/documents/374947/3413536/Anu\%C3\%A1rio+Estat\%C3\%ADstico+do+Mercado+Farmac\%C3\%AAutico+-+2016/485ddf50-a37f-469f-89e5-29643c5c9df5. Acesso em: 10 set. 2018.

ANVISA. Agência Nacional de Vigilância Sanitária. Anvisa e Inpi: acordo acelera análise de patentes. Brasília: Anvisa, 2017b. Disponível em: http://portal.anvisa.gov.br/noticias/-/asset_publisher/FXrpx9qY7FbU/content/anvisa-e-inpi-acordo-acelera-analise-de-patentes/219201/pop_up?_101_INSTANCE_FXrpx9qY7FbU_viewMode=print\&_101_INSTANCE_FXrpx9qY7FbU_languageld=pt_BR. Acesso em: 2 set. 2017.

ANVISA. Agência Nacional de Vigilância Sanitária. Medicamentos genéricos. 2018a. Disponível em: http://portal.anvisa.gov.br/ genericos. Acesso em: 3 set. 2018.

ANVISA. Agência Nacional de Vigilância Sanitária. Medicamentos genéricos: estatísticas e listas. 2018b. Disponível em: http:// portal.anvisa.gov.br/medicamentos-genericos-registrados. Acesso em: 5 set. 2018.

BARRAL, Welber; PIMENTEL, Luis Otávio. Direito de propriedade intelectual e desenvolvimento. In: BARRAL, Welber; PIMENTEL, Luis Otávio (org.). Propriedade intelectual e desenvolvimento. Florianópolis: Fundação Boiteux, 2006.

BASSO, Maristela. A tutela constitucional da propriedade intelectual na Carta de 1988: avanço indiscutível. Revista de Informação Legislativa, Brasília, a. 45, n. 179, jul./set. 2008. Disponível em: https://www2.senado.leg.br/bdsf/bitstream/handle/ id/176539/Tutela_constitucional_propriedade_intelectual.pdf?sequence=1. Acesso em: 17 out. 2018.

BERMUDEZ, Jorge Antonio Zepeda. Informação e regulamentação com qualidade: as bases para uma política de medicamentos genéricos. In: BERMUDEZ, Jorge Antonio Zepeda; BONFIM, José Ruben de Alcântara (org.). Medicamentos e a reforma do setor saúde. São Paulo: Hucitec; Sobravime, 1999. p. 179-191.

BRASIL. Constituição da República Federativa do Brasil de 1988. Disponível em: http://www.planalto.gov.br/ccivil_03/constituicao/constituicao.htm. Acesso em: 5 maio 2017.

BRASIL. Lei n. 9.279, de 14 de maio de 1996. Disponível em: http://www.planalto.gov.br/ccivil_03/leis/L9279.htm. Acesso em: 28 abr. 2018.

BRASIL. Superior Tribunal de Justiça. Recurso Especial 1.721.711-RJ. Relatora ministra Nancy Andrighi. Brasília: DJE, 20 abr. 2018. Disponível em: https://ww2.stj.jus.br/processo/revista/documento/mediado/?componente=ATC\&sequencial=82416191\&num_registro=201702619910\&data=20180420\&tipo=5\&formato=PDF. Acesso em: 8 abr. 2019.

BRASIL. Tribunal Regional Federal da 2a Região. Apelação e Reexame Necessário n. 0132260-18.2013.4.02.5101. Relator Andre Fontes. Publ. 15 jul. 2015. Disponível em: http://jurisprudencia.trf2.jus.br/sm/download?name=apolo-inteiro-teor\& id=2015,07,14,01322601820134025101_55467.pdf. Acesso em: 8 abr. 2019.

CHAVES, G. C.; OLIVEIRA, M. A. Direitos de propriedade intelectual e acesso a medicamentos. In: REIS, R.; TERTO JR., V.; PIMENTA, C.; MELLO, F. (org.). Propriedade intelectual: interfaces e desafios. Rio de Janeiro: Abia, 2007. p. 13-55.

CFF. Conselho Federal de Farmácia. Farmácias de elite. Brasília, 2016. Disponível em: http://www.cff.org.br/noticia. php?id=3879. Acesso em: 5 set. 2018.

INPI. Instituto Nacional da Propriedade Industrial. Resumo estatístico da situação dos pedidos de patentes. Rio de Janeiro: INPI, 2017. Disponível em: http://www.inpi.gov.br/sobre/estatisticas. Acesso em: 4 dez. 2017.

JORNAL Nacional. Inovar vai além de ter uma boa ideia: é preciso ousar e persistir. Ago. 2017. Disponível em: http://g1.globo.com/jornal-nacional/noticia/2017/08/inovar-vai-alem-de-ter-uma-boa-ideia-e-preciso-ousar-e-persistir.html. Acesso em: 3 set. 2017.

LISTA de Medicamentos Genéricos. O que são genéricos? Disponível em: http://medicamentogenerico.com.br. Acesso em: 3 set. 2018. 
OLIVEIRA, Ubirajara Mach de. A proteção jurídica das invenções de medicamentos e de gêneros alimentícios. Porto Alegre: Síntese, 2000.

PAESANI, Liliana Minardi. Manual de propriedade intelectual: direito de autor, direito da propriedade industrial, direitos intelectuais sui generis. São Paulo: Atlas, 2012.

PIMENTEL, Luís Otávio. Direito de propriedade intelectual e desenvolvimento: considerações para o debate. Cadernos de Direito, Piracicaba, p. 7-25, dez. 2004. Disponível em: https://www.metodista.br/revistas/revistas-unimep/index.php/cd/article/ view/726/286. Acesso em: 27 abr. 2018.

PRÓ-GENÉRICOS. Medicamento genérico: uma importante conquista para a saúde pública no Brasil. Disponível em: http:// www.progenericos.org.br/pdf/Medicamento_Generico_15anos.pdf. Acesso em: 10 set. 2018.

PRONER, Carol. Propriedade intelectual e direitos humanos: sistema internacional de patentes e direito ao desenvolvimento. Porto Alegre: Sergio Antonio Fabris, 2007.

SILVA, José Afonso da. Curso de direito constitucional positivo. 38. ed. São Paulo: Malheiros, 2014.

SPADANO, Lucas; SANTOS, Bernardo; TÂNGARI, Luiza. Inpi reforça medidas contra acúmulo de patentes pendentes de exame. Revista Consultor Jurídico, 21 ago. 2017.

UNITED NATIONS. Economic and Social Council. General Comment, n. 7, 2005. Disponível em: http://docstore.ohchr.org/SelfServices/FilesHandler.ashx?enc=4sIQ6QSmIBEDzFEovLCuW1aOSzab0oXTdImnsJZZVQcMZjyZIUmZS43h49u0CNAuJljwgfzCL8JQ1SHYTZH6jsZteqZOpBtECZh96hyNh\%2F\%2FHW6g3fYyiDXsSgaAmIP\%2BP. Acesso em: 16 out. 2018.

WHO. World Health Organization. The Rational Use of Drugs. In: Report of the Conference of Experts. Nairobi: WHO, nov. 1985. Disponível em: http://apps.who.int/medicinedocs/documents/s17054e/s17054e.pdf. Acesso em: 6 set. 2018. 